\title{
Reaction kinetics on supported model catalysts: Molecular beam/in situ time- resolved infrared reflection absorption spectroscopy study of the CO oxidation on alumina supported Pd particles
}

Cite as: Journal of Vacuum Science \& Technology A 19, 1516 (2001); https://doi.org/10.1116/1.1345910

Submitted: 07 September 2000 . Accepted: 11 December 2000 . Published Online: 13 July 2001

J. Libuda, I. Meusel, J. Hoffmann, J. Hartmann, and H.-J. Freund

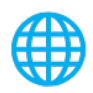

\section{ARTICLES YOU MAY BE INTERESTED IN}

The $\mathrm{CO}$ oxidation kinetics on supported Pd model catalysts: A molecular beam/in situ timeresolved infrared reflection absorption spectroscopy study

The Journal of Chemical Physics 114, 4669 (2001); https://doi.org/10.1063/1.1342240

A molecular beam/surface spectroscopy apparatus for the study of reactions on complex model catalysts

Review of Scientific Instruments 71, 4395 (2000); https://doi.org/10.1063/1.1318919

Surface selection rules

The Journal of Chemical Physics 77, 4408 (1982); https://doi.org/10.1063/1.444442

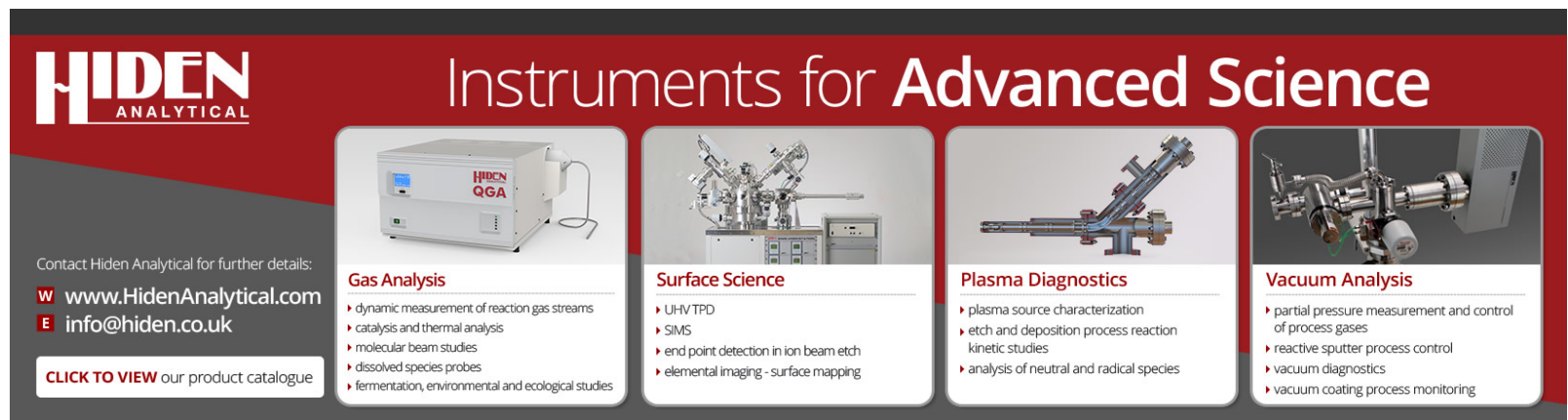




\title{
Reaction kinetics on supported model catalysts: Molecular beam/in situ time-resolved infrared reflection absorption spectroscopy study of the $\mathrm{CO}$ oxidation on alumina supported Pd particles
}

\author{
J. Libuda, ${ }^{\text {a) }}$ I. Meusel, J. Hoffmann, J. Hartmann, and H.-J. Freund \\ Fritz-Haber-Institut der Max-Planck-Gesellschaft, Faradayweg 4-6, D-14195 Berlin, Germany
}

(Received 7 September 2000; accepted 11 December 2000)

\begin{abstract}
By combining molecular beam techniques and time-resolved infrared reflection absorption spectroscopy (TR-IRAS) we have studied the kinetics of the $\mathrm{CO}$ oxidation reaction on an alumina-supported Pd model catalyst. The Pd particles are deposited by metal evaporation under ultrahigh vacuum conditions onto a well-ordered alumina film, prepared on a $\mathrm{NiAl}(110)$ single crystal. Particle size, density, and structure of the Pd deposits have been characterized in previous studies. In the low temperature region, transient and steady-state experiments have been performed over a wide range of $\mathrm{CO}$ and oxygen fluxes by crossing two effusive molecular beams on the sample surface. We determine the steady-state $\mathrm{CO}_{2}$ production rate as a function of the $\mathrm{CO}$ fraction in the impinging gas flux. Simultaneously, the occupation of CO adsorption sites under steady-state conditions is monitored by in situ infrared spectroscopy. The origin of different types of $\mathrm{CO}_{2}$ transients is discussed. In particular we focus on the transient $\mathrm{CO}_{2}$ production after switching off the $\mathrm{CO}$ beam. For the model catalyst investigated, detailed reaction rate measurements in combination with TR-IRAS show that the origin of the particular transient behavior of the supported model system is not due to the presence of specific adsorption sites on small particles, as has been proposed previously. Instead, we suggest that the transient behavior is a consequence of the inhibition of the dissociative adsorption of $\mathrm{O}_{2}$ at high $\mathrm{CO}$ coverage. Additionally, the inherent heterogeneity of the supported particle system can enhance the observed effect. (C) 2001 American Vacuum Society.
\end{abstract} [DOI: 10.1116/1.1345910]

\section{INTRODUCTION}

Heterogeneous catalysts are typically complex systems with properties sensitively depending on their composition and preparation procedure. ${ }^{1}$ Specifically with respect to supported metal catalysts, it is widely accepted that the activity and selectivity of those systems may be strongly influenced by the support and the particle size. ${ }^{2}$ Many concepts have been proposed which may possibly explain the molecular origin of the modified reaction kinetic kinetics. Among these are, e.g., size effects, geometrical effects due to the presence of specific adsorption sites or the combination of adsorption sites, the influence of boundary sites at the metal oxide interface, metal support interactions, or support effects. One aspect, which makes the reaction kinetics on supported catalyst inherently different from single crystal surfaces, is the simultaneous presence of a variety of nonequivalent sites in close proximity, such as different crystallite facets, edge, defect, or particle boundary sites. In recent Monte Carlo simulations, Zhdanov and Kasemo have demonstrated that the coupling by diffusion between such nonequivalent adsorption sites might substantially alter the observed reaction rates. $^{3-5}$

Unfortunately, specific experimental evidences for the concepts mentioned before are extremely scarce. This is due to the fact that real catalysts are usually hardly accessible to surface science experiments and their vast complexity often

\footnotetext{
a) Author to whom correspondence should be addressed; electronic mail: libuda@fhi-berlin.mpg.de
}

precludes an assignment to specific microscopic properties. On the other hand, the effects will not be present on experimentally easily accessible single crystal surfaces. To overcome this so called "materials gap" between surface science and catalysis, 6,7 a variety of supported model catalysts have been developed. These models allow us to introduce certain aspects of a real catalysts in a more controlled fashion, while still maintaining the experimental accessibility. ${ }^{7-12}$

The development of such model systems requires several steps, as can be illustrated for the $\mathrm{Pd} / \mathrm{Al}_{2} \mathrm{O}_{3} / \mathrm{NiAl}(110)$ catalyst employed in this work: First, the structure and defect structure as well as the adsorption properties of the $\mathrm{Al}_{2} \mathrm{O}_{3}$ film were investigated. ${ }^{13-15}$ Subsequently, the growth, geometric structure, and electronic structure of Pd particles supported on this film and their adsorption properties have been addressed in a series of studies. ${ }^{7,9,10,12,16-18}$ Based on this work we finally attempt to establish a correlation between the structure and the microscopic kinetics.

Providing a maximum of control over the reactants, molecular beam techniques represent the method of choice in this type of microkinetic studies. ${ }^{19-22}$ Ertl and Engel ${ }^{23,24}$ earlier applied beam methods to study the kinetics of the $\mathrm{CO}$ adsorption and oxidation and on $\operatorname{Pd}(111)$ and a variety of similar studies on other single crystal surfaces have been published since (see, e.g., Refs. 25-27). In spite of the successful experiments on single crystals, similar beam studies on supported catalysts are, however, scarce and contradictory (see e.g., Ref. 8). In many cases it remains unclear to what 
extent size effects may influence the kinetics and energetics of the reaction. ${ }^{28-32}$

Becker and Henry investigated the $\mathrm{CO}$ oxidation on $\mathrm{Pd} /$ $\mathrm{MgO}(100)$ by molecular beam methods. ${ }^{31,32}$ They related transient $\mathrm{CO}_{2}$ peaks in the reaction rate to defect adsorption. In this study, we apply an experimental approach combining molecular beam techniques and time-resolved infrared reflection absorption spectroscopy (TR-IRAS). It is shown that a similar transient $\mathrm{CO}_{2}$ peak, which is also found for the present model system, is not related to strong defect adsorption. Instead we discuss alternative explanations, including the role of the strong inhibition of oxygen adsorption by $\mathrm{CO}$ and the effect of the heterogeneity of the supported model catalyst.

\section{EXPERIMENT}

All experiments were performed in a new ultrahigh vacuum molecular beam/surface spectroscopy apparatus, which has been described in the literature recently. ${ }^{33}$ The system has been specifically designed for kinetic studies on complex model systems. It offers the experimental possibility of up to three beams being crossed on the sample surface. The $\mathrm{CO}$ and $\mathrm{O}_{2}$ beams, which were used in the work presented here, are generated by two effusive sources based on multichannel arrays. This design allows an easy variation of the beam intensities over several orders of magnitude, without any change in the beam properties. Beam modulation is provided by a computer-controlled shutter located inside the second pumping stage of the beam sources. To avoid artifacts due to only partial overlap, the beam diameter was chosen such that it exceeds the sample surface. Both sources were operated at room temperature. High purity oxygen (AGA, >99.999\%) and CO (AGA, >99.996\%) were used. The latter was further purified using a liquid $\mathrm{N}_{2}$ cold trap. Angular-integrated gas phase measurements were performed with a quadrupole mass spectrometer (ABB Extrel) which is not in line-of-sight of the sample. The gas phase detection can be combined with time-resolved in situ Fourier transform infrared (FT-IR) reflection absorption spectroscopy (TR-IRAS) employing a vacuum FT-IR spectrometer (Bruker). For the time-resolved spectra with a temporal resolution of $1 \mathrm{~s}$ several transients were accumulated to improve the signal-to-noise $(\mathrm{S} / \mathrm{N})$ ratio. For this purpose the beam shutter was synchronized with the recording of the IR spectra. For a detailed description of the experimental details we again refer to the literature. ${ }^{33}$ All spectra were recorded at a spectral resolution of $8 \mathrm{~cm}^{-1}$.

Briefly, the sample was prepared by sputtering and annealing of a $\mathrm{NiAl}(110)$ single crystal, followed by an oxidation and annealing procedure, the details of which are given elsewhere. ${ }^{13,14}$ The cleanliness and quality of the oxide film was checked via (low energy electron diffraction and Auger electron spectroscopy. Before the actual experiment, the active metal component $(\mathrm{Pd},>99.9 \%)$ was deposited under well controlled conditions by evaporation from a rod using a commercial evaporator (Focus) based on electron bombardment. During deposition, the crystal was biased with a re-
TABLE I. Preparation conditions and structural parameters for the Pd particles on $\mathrm{Al}_{2} \mathrm{O}_{3} / \mathrm{NiAl}(110)$

\begin{tabular}{ll}
\hline $\begin{array}{l}\text { Deposition parameters } \\
\left.\text { Pd coverage (atoms } \mathrm{cm}^{-2}\right)\end{array}$ & $2.7 \times 10^{15}$ \\
Deposition temperature $(\mathrm{K})$ & 300 \\
$\quad$ Deposition rate $\left(\right.$ atoms $\left.\mathrm{cm}^{-2} \mathrm{~s}^{-1}\right)$ & $9 \times 10^{12}$ \\
& \\
Structural parameters & $1.0( \pm 0.2) \times 10^{12 \mathrm{a}, \mathrm{b}}$ \\
$\quad$ Island density $\left(\mathrm{cm}^{-2}\right)$ & $\sim 2700^{\mathrm{a}, \mathrm{b}}$ \\
$\quad$ Number of Pd atoms/island & $\sim 0.20( \pm 0.02)^{\mathrm{c}}$ \\
$\quad \begin{array}{l}\text { Estimated fraction } \\
\text { of support covered by Pd }\end{array}$ & $0.20( \pm 0.03)^{\mathrm{c}}$ \\
Estimated fraction & \\
$\quad \begin{array}{l}\text { of surface Pd atoms } \\
\text { Average island size: }\end{array}$ & $\sim 5.5 \pm 0.7 \mathrm{~nm}$ \\
$\quad$ Epitaxial orientation & $(111)^{\mathrm{a}}$ \\
$\quad$ Island structure & crystalline, predominantly (111) \\
& facets, small fraction of \\
& $(100)$ facets
\end{tabular}

${ }^{\mathrm{a} S e e}$ Ref. 16.

${ }^{\mathrm{b}}$ See Ref. 30

${ }^{\mathrm{c}} \mathrm{See}$ Ref. 48

${ }^{\mathrm{d}}$ See Ref. 18

tarding voltage in order to prevent ions from being accelerated toward the sample (point defect creation). The evaporator flux was calibrated by a quartz microbalance prior to use.

\section{RESULTS AND DISCUSSION}

\section{A. Characterization of the supported Pd model catalyst}

Previously, the growth and structure of Pd deposits as well as other metals on $\mathrm{Al}_{2} \mathrm{O}_{3} / \mathrm{NiAl}(110)$ have been studied over a wide range of conditions and the results have been extensively reviewed. ${ }^{9}, 10,16-18$ In this work we will focus on one particular set of preparation conditions, for which detailed information on both the particle size and density and on the particle structure is available. The deposition and selected structure parameters are summarized in Table I. We will briefly review the structural features. In Fig. 1 scanning tunneling microscopy (STM) images ${ }^{30}$ are displayed. The Pd particles form three dimensional islands; their density typically amounts to $1 \times 10^{12}$ islands $\mathrm{cm}^{-2}$. From this number it can be estimated that the average Pd particle will contain about 2700 atoms, corresponding to an average particle diameter of $5.5 \pm 0.7 \mathrm{~nm}$ (note that due to tip effects the particles in Fig. 1 appear larger than their actual size). In the closeup shown in Fig. 1(b), it becomes evident that most of the Pd particles exhibit the well-defined morphology of a nanocrystallite. The particles grow in (111) orientation, preferentially exposing (111) facets and only a small fraction of (100) facets. The regular structure of the Pd crystallites has been demonstrated in a recent STM study showing atomic resolution both on the top and side facets of the particles. ${ }^{18}$ Before the kinetic experiments the particles were stabilized by extended oxygen exposure (typically $\sim 100 \mathrm{~L}, 1 \mathrm{~L}=1$ $\times 10^{-6}$ Torrs). Previously, this stabilization procedure has been shown to be necessary to obtain stable oxidation 


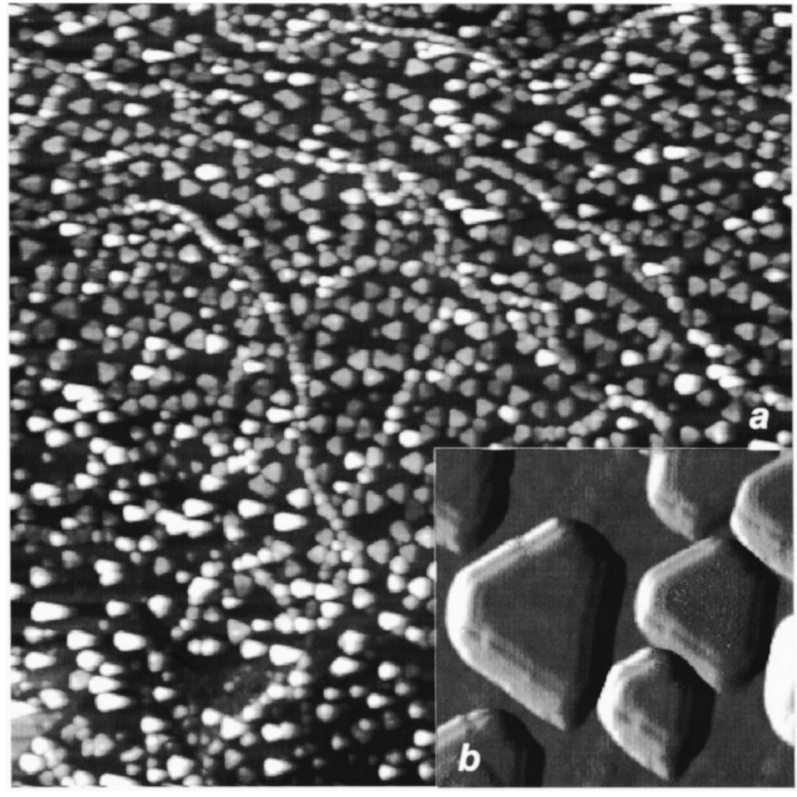

FIG. 1. (a) STM image constant current topography [(CCT) $3000 \AA \times 3000$ $\AA]$ of the Pd particles grown at $300 \mathrm{~K}$ on $\mathrm{Al}_{2} \mathrm{O}_{3} / \mathrm{NiAl}(110)$, from Ref. 30 ; (b) differentiated close-up STM image of the Pd particles (CCT, $200 \AA \times 200 \AA$ ), from Ref. 30 .

kinetics. ${ }^{30}$ It was demonstrated that the process is connected to a bulk diffusion process under the reaction conditions. As observed by STM, ${ }^{30}$ neither the particle density nor the particle shape are significantly affected by this procedure.

In a series of experiments it has been shown that the $\mathrm{Pd}$ particles in many ways resemble the typical properties of a $\mathrm{Pd}(111)$ surface. For example, we have probed the $\mathrm{CO}$ adsorption/desorption kinetics employing modulated molecular beam techniques and have determined activation energies for desorption which are in good agreement with $\operatorname{Pd}(111)$ single crystal data. ${ }^{24}$ Also, the thermal desorption spectra for $\mathrm{CO}^{16,34}$ are similar to those of $\operatorname{Pd}(111)^{35}$ and so are the activation barriers for the Langmuir-Hinshelwood reaction step in the $\mathrm{CO}$ oxidation. ${ }^{30}$

A final remark before discussing the reactivity measurements is related to the catalyst stability under the reaction conditions applied in this study. Processes that may influence the catalytic activity include (a) structural rearrangements or changes in the particle dispersion and (b) a buildup of surface carbon as a result of $\mathrm{CO}$ dissociation. ${ }^{36}$ In order to probe whether there is a significant deactivation on the time scale of the experiment, we have performed transient reactivity measurements of the type shown in the following section in regular intervals and under identical conditions. There was no indication for a significant deactivation of the model catalysts within the reaction times and gas exposures used in this work. Minor variations in the transient behavior were related to the initial bulk diffusion process of oxygen. ${ }^{37}$

\section{B. General types of transient behavior}

Before we will come to a systematic discussion of the transient and steady-state behavior of the $\mathrm{CO}$ oxidation, we

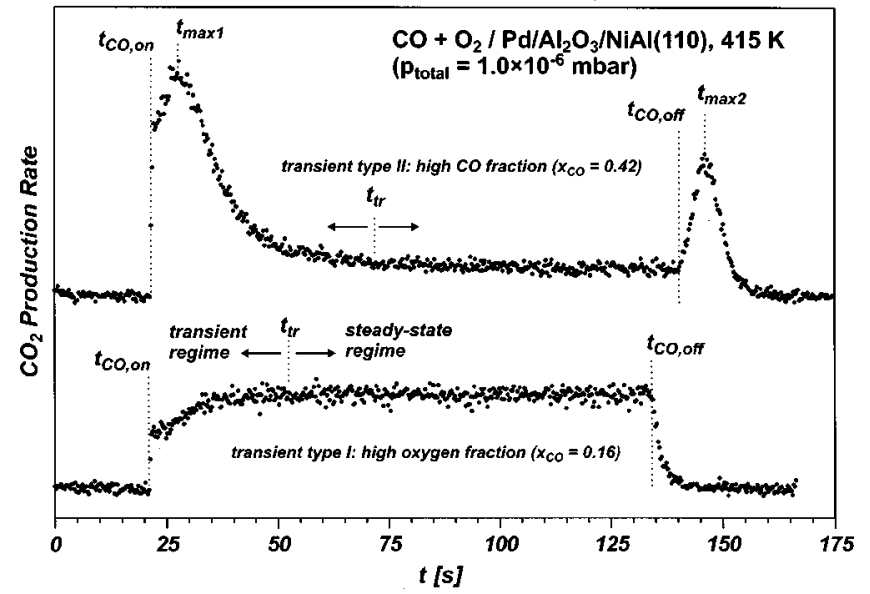

FIG. 2. Transient behavior of the $\mathrm{CO}_{2}$ production rate (continuous $\mathrm{O}_{2}$ beam and a modulated $\mathrm{CO}$ beam) under $\mathrm{CO}$-rich conditions (upper trace, transient type II) and $\mathrm{O}_{2}$-rich conditions (lower trace, transient type I) $\left(T_{\text {Sample }}=415 \mathrm{~K}, p_{\text {total }}=1.0 \times 10^{-6} \mathrm{mbar}\right)$.

will give a short description on how most of the experiments in this study were performed and how the different types of transients can be qualitatively understood.

The general types of $\mathrm{CO}_{2}$ transients are shown in Fig. 2. The corresponding experiments were performed in the following manner: After preparation and stabilization of the model system, the surface is continuously exposed to an $\mathrm{O}_{2}$ beam with a beam flux $F_{\mathrm{O}_{2}}$, generated by one of the effusive beam sources. Simultaneously, the integral $\mathrm{CO}_{2}$ production rate is recorded. At a time $t_{\mathrm{CO} \text {,on }}$ a $\mathrm{CO}$ beam with a beam flux $F_{\text {CO }}$, generated by the second effusive source, is switched on. As flux parameters we define: (1) $x_{\mathrm{CO}}$, the $\mathrm{CO}$ fraction with respect to the total flux, as $x_{\mathrm{CO}}=F_{\mathrm{CO}} /\left(F_{\mathrm{CO}}+F_{\mathrm{O}_{2}}\right)$ and (2) $p_{\text {total }}=p_{\mathrm{CO}}+p_{\mathrm{O}_{2}}$, the total effective pressure of $\mathrm{CO}$ and $\mathrm{O}_{2}$ at the sample position $\left(F_{i}\right.$ : partial flux of component $i$ at the sample position). Typically, in a series of experiments, the CO flux fraction was varied, whereas the other parameters such as the total effective pressure and the sample temperature were kept constant.

In general, two different types or transients can be observed as a function of $x_{\mathrm{CO}}$, which we will denote as type 1 and type 2 (see Fig. 2), respectively (see also Refs. 38 and 39).

Type 1: If the experiment is performed at low $\mathrm{CO}$ and high $\mathrm{O}_{2}$ flux, a simple type of transient behavior is observed as displayed in the lower trace in Fig. $2\left(x_{\mathrm{CO}}=0.16\right)$. We start from a situation, in which the system has reached its oxygen saturation coverage under the given flux and temperature conditions. Upon switching on the $\mathrm{CO}$ beam $\left(t_{\mathrm{CO} \text {,on }}\right)$, we find an instantaneous increase in the $\mathrm{CO}_{2}$ production (on the time scale of the experiment). As pointed out by Piccolo et al. ${ }^{39}$ this is due to the rapid formation of a steady-state precursor coverage. Note that the steady-state coverage of the physisorbed precursor state is extremely low and that the corresponding adsorption-desorption equilibrium is established on a time scale well below the experimental resolution. From this precursor, the $\mathrm{CO}$ molecule 


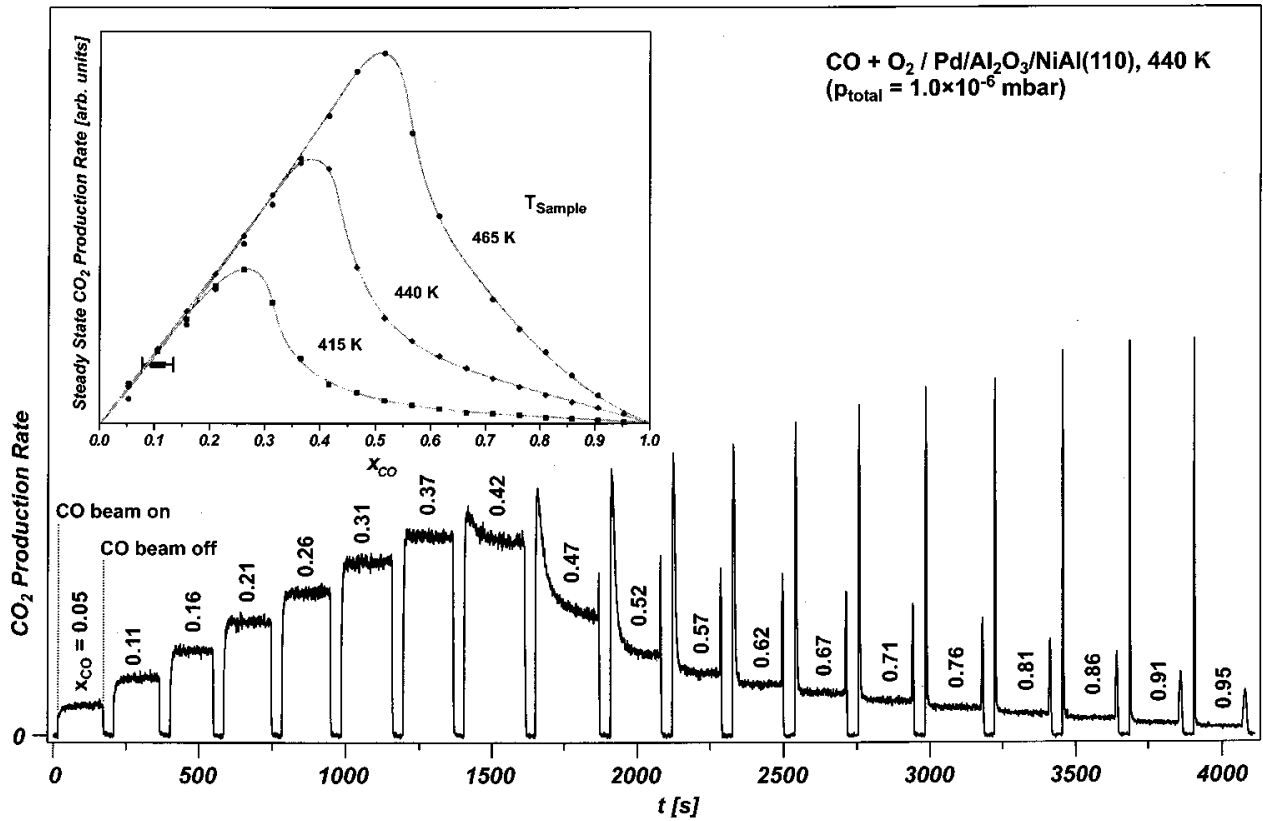

FIG. 3. Transient behavior of the $\mathrm{CO}_{2}$ production rate as a function of the $\mathrm{CO}$ fraction in the impinging gas flux $x_{\mathrm{CO}}\left(T_{\text {Sample }}=440 \mathrm{~K}, p_{\text {total }}=1.0 \times 10^{-6}\right.$ mbar). The inset shows the steadystate $\mathrm{CO}_{2}$ production rate as a function of the $\mathrm{CO}$ fraction in the impinging gas flux $x_{\mathrm{CO}}\left(p_{\text {total }}=1.0 \times 10^{6} \mathrm{mbar}\right)$. may either desorb or chemisorb and subsequently react to $\mathrm{CO}_{2}$. In the course of the reaction oxygen vacancies are generated, which lead to an increased adsorption probability for the $\mathrm{CO}$ precursor and thus an increase in the reaction rate. After this transient period $t_{\text {tr }}$, the system finally reaches the steady-state reaction conditions. Please note that the steady state is characterized by a high oxygen coverage and a small $\mathrm{CO}$ coverage. After switching off the $\mathrm{CO}$ beam $\left(t_{\mathrm{CO} \text {,off }}\right)$, the adsorbed $\mathrm{CO}$ is consumed and the $\mathrm{CO}_{2}$ production rate decreases continuously.

Type 2: If an equivalent experiment is performed at sufficiently high $\mathrm{CO}$ fraction (Fig. 2, upper trace, $x_{\mathrm{CO}}=0.42$ ), a different behavior is found. Again, starting from an oxygen saturated surface, we observe an instantaneous increase in the $\mathrm{CO}_{2}$ production rate upon switching on the $\mathrm{CO}$ beam. Subsequently, the reaction rate increases slowly until it reaches a first maximum $\left(t_{\max 1}\right)$. As for transient type 1 , the increasing reaction rate can be explained by an increasing chemisorption probability of the $\mathrm{CO}$ precursor, due to the decreasing oxygen coverage. ${ }^{39}$ Once a certain $\mathrm{CO}$ coverage is reached, however, the $\mathrm{CO}$ oxidation rate decreases again as a result of the strongly inhibiting effect of $\mathrm{CO}$ on the $\mathrm{O}_{2}$ adsorption. ${ }^{40}$ Finally, a steady state is reached, which is characterized by a high $\mathrm{CO}$ coverage and a low reaction rate (due to the inhibiting effect of $\mathrm{CO}$ ). Once the $\mathrm{CO}$ beam is terminated $\left(t_{\mathrm{CO} \text {,off }}\right)$, the process is reversed: the adsorbed $\mathrm{CO}$ is consumed in the course of the reaction, leaving free adsorption sites for $\mathrm{O}_{2}$ adsorption. Thus the $\mathrm{O}_{2}$ adsorption is accelerated and so is the reaction rate, which reaches a maximum $\left(t_{\max 2}\right)$, before it finally decreases due to depletion of the $\mathrm{CO}$ reservoir.

\section{Systematic studies of the transient behavior and steady-state $\mathrm{CO}_{2}$ production}

In order to obtain a general overview over the reaction behavior we have performed a series of transient beam ex- periments at different reaction temperatures. A typical series of experiments at a sample temperature of $440 \mathrm{~K}$ is displayed in Fig. 3. The sample is exposed to a continuous oxygen beam. Its intensity is chosen such that the total effective pressure after switching on the $\mathrm{CO}$ beam was $p_{\text {total }}=1.0 \times 10^{-6}$ mbar. The CO flux fraction $x_{\mathrm{CO}}$ was varied between 0.05 and 0.95 and for each $x_{\mathrm{CO}}$ a transient was recorded.

In general, we find the two types of transient behavior discussed in Sec. III B. For $x_{\mathrm{CO}} \leqslant 0.37$ the transients are of type 1 (oxygen rich), whereas for $x_{\mathrm{CO}} \geqslant 0.47$ we find a $\mathrm{CO}$ rich steady stade, connected with the characteristic reaction rate maxima (type 2 ).

Before we come to the transition between the two regimes, we will briefly consider some basic features of the experiment: With respect to the characteristics of the first transient $\mathrm{CO}_{2}$ peak, it is found that the time constant at which the steady state is reached after switching on the $\mathrm{CO}$ beam diverges close to the transition region. This is easy to understand as the $\mathrm{CO}$ coverage is built up by the excess of adsorbed $\mathrm{CO}$ (not consumed during the reaction), which vanishes at the transition between the two regimes. The integral below the transient peak, however, remains nearly constant for $x_{\mathrm{CO}} \geqslant 0.52$. This is explained by the fact that the peak integral roughly corresponds to the oxygen precoverage, which is constant and will be fully consumed during the reaction. Contrary to the first transient peak, the width of the second transient peak (upon switching off) increases with increasing $x_{\mathrm{CO}}$ since the $\mathrm{O}_{2}$ flux and therefore the reaction rate decreases. It corresponds to the fraction of $\mathrm{CO}$ adsorbed in the steady state that upon termination of the $\mathrm{CO}$ beam will not desorb but react to $\mathrm{CO}_{2}$. In general, it will show a steplike behavior similar to the first transient peak. In contrast to the adsorbed oxygen, the $\mathrm{CO}$, however, may desorb on the time scale of the reaction at high reaction temperatures and 
low $\mathrm{O}_{2}$ flux, which may lead to a decreasing peak integral at high $x_{\mathrm{CO}}$.

From the transients we can derive a plot of the steadystate reaction rates as a function of the $\mathrm{CO}$ flux fraction $x_{\mathrm{CO}}$ (inset in Fig. 3), which qualitatively can be understood as follows: At low $x_{\mathrm{CO}}$, the $\mathrm{CO}_{2}$ production is roughly proportional to the $\mathrm{CO}$ partial pressure. It reflects the sticking coefficient of $\mathrm{CO}$ under the particular steady-state conditions (high oxygen and low $\mathrm{CO}$ coverage). At a certain critical $x_{\mathrm{CO}}$, the system switches from an oxygen-rich to a CO-rich steady state. The transition is connected to a sudden decrease in the reaction rate as a consequence of the inhibiting effect of $\mathrm{CO}$ on the dissociative adsorption of $\mathrm{O}_{2}$ (see e.g., Refs. 3, 40, and 41 and references therein).

Comparing the three different reaction temperatures displayed, we find that in the low CO coverage region, the reaction rate is almost independent of the reaction temperature. Generally, the CO sticking coefficient, which governs the reaction rate, is expected to decrease slightly with increasing temperature due to the decreasing lifetime of the $\mathrm{CO}$ precursor state both on the alumina substrate and on the Pd particles. This effect, however, is too weak to be identified clearly from the present data. Note that although the $\mathrm{CO}$ steady-state coverage is small, it will depend on the reaction temperature, i.e., the steady-state $\mathrm{CO}$ coverage will increase with decreasing surface temperature. Thus, at low temperature the transition point, at which due to inhibition of oxygen adsorption the system switches to the CO-rich state, is reached at lower $x_{\mathrm{CO}}$. In the high $\mathrm{CO}$ coverage region the rate is limited by the $\mathrm{O}_{2}$ adsorption step. The reaction rates do not coincide due to the increased CO coverage at lower temperatures (increased inhibition).

Recently, we have shown that both the steady state and the transient reaction rate can be semiquantitatively simulated using a simple homogeneous surface model. ${ }^{37}$ In future work, the data of the type presented here may provide a basis for more extensive microkinetic simulations of the steady state and transient reaction behavior. It should be pointed out that such simulations - in connection with steady-state reaction rate measurements for different types of structurally well-characterized supported model catalysts-may provide a tool to identify kinetic effects characteristic of supported nanoparticles. ${ }^{3}$

\section{Transient CO switching-off behavior}

Among the different kinetic effects on supported catalysts, surface diffusion mediated coupling between different types of adsorption sites has recently attracted considerable attention. ${ }^{3-5}$ The presence of different types of adsorption sites in close proximity is an intrinsic property of complex catalytic systems. Such types of adsorption sites may, e.g., be different facets on nanocrystallites, step, edge, or other defect sites, interface sites located at the particle boundary or adsorption sites on the support material itself. Still, the experimental verification of these effects is not straightforward and very few examples exist in the literature.
Recently, Becker and Henry have observed a transient behavior in an experiment, similar to the transient experiments shown in this work, which was related to such a heterogeneity effect: ${ }^{8,31,32}$ Upon switching off the CO beam, they found an initial sudden decrease of the $\mathrm{CO}_{2}$ production rate, followed by a smaller $\mathrm{CO}_{2}$ production peak. Originally, they suggested an explanation, which involves rapid desorption of $\mathrm{CO}$ from regular sites (resulting in the rapid decrease in $\mathrm{CO}_{2}$ production). Based on previous studies, ${ }^{42,43} \mathrm{CO}$ adsorbed at low coordinated edge sites was assumed to be bound more strongly. Thus these sites would remain fully saturated until the CO reservoir on the facets is largely depleted. Only after vacancies among these defects are generated does the reaction rate increase again, resulting in a smaller maximum in the $\mathrm{CO}_{2}$ production rate.

Since the Pd crystallites in the present study are composed of similar (111) and (100) facets, the effect should also be present on the model system used in this work. We have, therefore, investigated the transient behavior under a variety of flux and temperature conditions. Indeed, we find that under certain flux conditions we observe a transient $\mathrm{CO}_{2}$ peak (Fig. 4), which appears very similar to the effect originally reported.

To further investigate the origin of the peak, we have systematically varied the $\mathrm{CO}$ flux fraction $x_{\mathrm{CO}}$ between both reaction regimes. The result for two reaction temperatures is displayed in Fig. 4. The effect only starts to appear close to the transition between the oxygen-rich and the CO-rich reaction regime and depends strongly on the experimental conditions. The inset shows the integral $\mathrm{CO}_{2}$ production in the switching off peak: as a function of $x_{\mathrm{CO}}$ the intensity varies continuously. At high $\mathrm{CO}$ ratio it develops into the typical transient peak observed at high CO flux. At low CO fraction it first decreases and finally vanishes completely.

In contrast to the previously suggested explanation, this continuous intensity variation indicates that the effect, at least for the present supported model catalyst, is not related to a characteristic type of defect site connected to the $\mathrm{Pd}$ particle size. Instead, the effect appears to involve all $\mathrm{CO}$ adsorption sites available on the particle.

The crucial point with respect to the previous explanation is that the sudden decrease in the reaction rate is related to the spontaneous desorption of $\mathrm{CO}$ upon termination of the CO beam. To verify whether such an effect exists, we have performed time-resolved in situ IRAS experiments [Fig. 5(b)] simultaneously with the reactivity measurements [Fig. 5(a)]: Under these conditions, where the sudden decrease and the transient peak are observed, we have recorded the IR absorption spectra with a temporal resolution of $1 \mathrm{~s}$. In order to improve the $\mathrm{S} / \mathrm{N}$ ratio the full reaction sequence was automatically repeated and accumulated (five scans in Fig. 5).

A detailed discussion of the IR spectra can be found in the literature. ${ }^{17,37,44}$ Briefly, two features are observed in the frequency region which is typical for $\mathrm{CO}$ adsorbed in bridge and hollow sites (Fig. 5, Nos. 2 and 3). Absorption from on-top CO is hardly detectable (Fig. 5, No. 1). The features were integrated as a function of time and the results are 


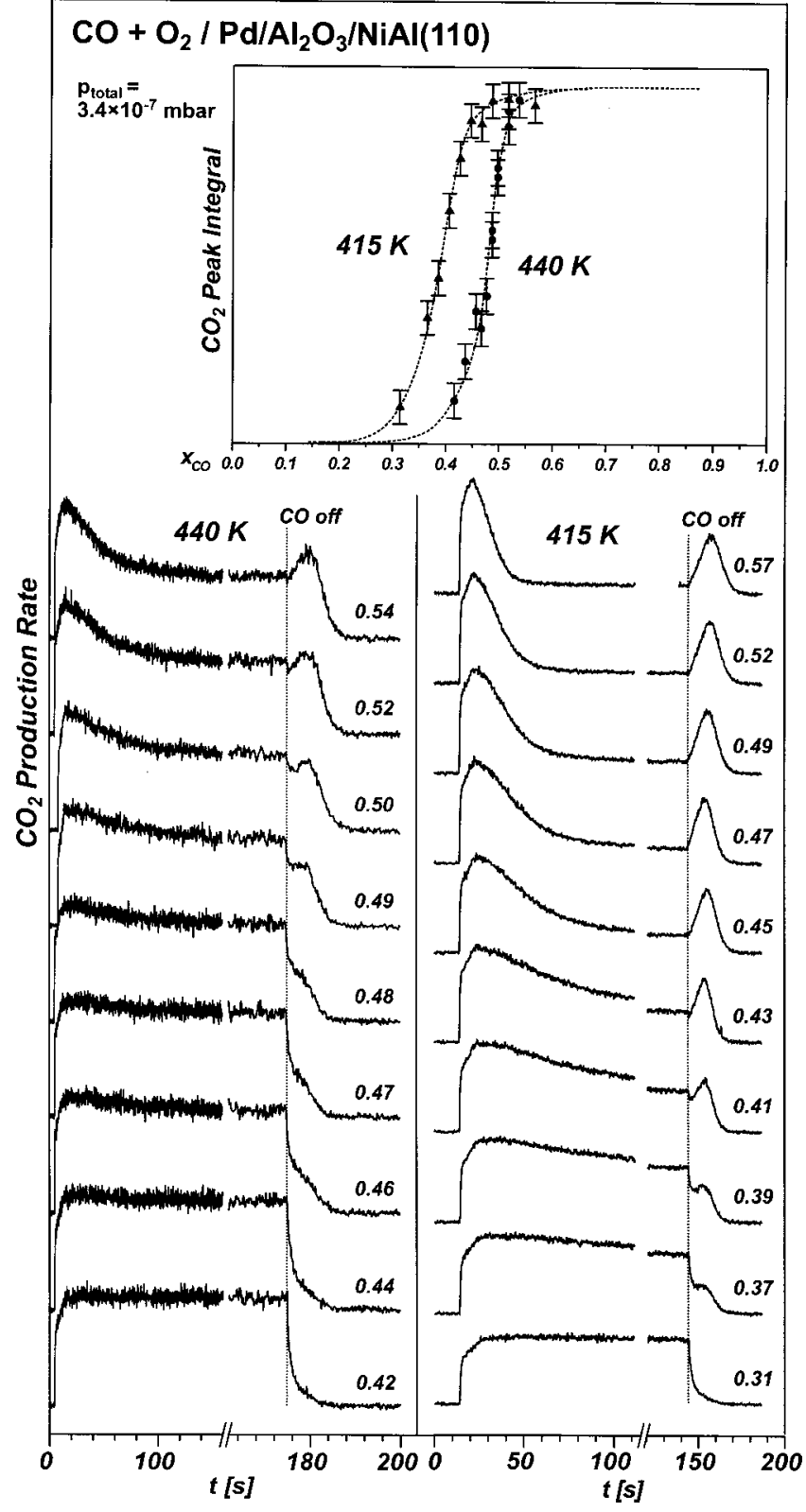

FIG. 4. Transient behavior of the $\mathrm{CO}_{2}$ production rate as a function of the $\mathrm{CO}$ fraction in the impinging gas flux $x_{\mathrm{CO}}$ close to the transition between the two reaction regimes ( $p_{\text {total }}=3.4 \times 10^{-7}$ mbar). The inset shows the integral over the peak which appears upon termination of the $\mathrm{CO}$ beam.

shown in the inset [Fig. 10(c)]. No indication for a sudden decrease in the $\mathrm{CO}$ absorption signal is found. Instead the absorption peaks decrease continuously with a slope roughly resembling the reaction rate (note that due to the nonlinear coverage-absorption dependence there is no simple correspondence between the two quantities, see e.g., Ref. 45).

In line with the previous intensity argument (Fig. 4), this result clearly demonstrates that the observed behavior cannot be a consequence of spontaneous $\mathrm{CO}$ desorption from regular sites and strong binding to defect sites. Instead, the effect appears to be related to the simple $\mathrm{CO}_{2}$ production peak under conditions of high $\mathrm{CO}$ flux. This suggestion is consistent with an estimate of the $\mathrm{CO}$ surface residence times based on the desorption, which predicts residence times of $200 \mathrm{~s}$ $(20 \mathrm{~s})$ for a surface temperatures of $415 \mathrm{~K}(440 \mathrm{~K})$ at low CO coverage. ${ }^{37}$

\section{E. Discussion}

The experiments have shown that the discussed $\mathrm{CO}_{2}$ peak: (1) starts to appear only in the transition region between the two reaction regimes and (2) is not related to strong adsorption at specific defect sites. Taking this into account we may consider the following alternative explanations, which may give rise or additionally contribute to the observed effect.

Local beam intensity variations: Due to beam intensity variations in the $\mathrm{CO}$ and $\mathrm{O}_{2}$ beam, the sample surface will locally be exposed to different effective pressures and flux ratios. From beam profile measurements, a standard deviation of the local pressure $p_{\text {eff }}$ of typically $\pm 6 \%$ can be estimated. The standard deviation of the flux ratio $x_{\mathrm{CO}}$ is typically $\pm 2 \%$. The width of the transition region (see Fig. 4), however, is significantly broader (typically in the order of $\pm 10 \%$ of the $x_{\mathrm{CO}}$ value at which the transition occurs). Thus, in a first approximation we may neglect this contribution.

CO poisoning induced peaks: We have recently demonstrated that the transient behavior can be semiquantitatively simulated using a simple homogeneous "mean-field" model based on kinetic parameters from separate adsorption and reactivity studies on $\mathrm{Pd}(111)$ and supported $\mathrm{Pd}$ particles. ${ }^{37}$ The transient $\mathrm{CO}_{2}$ production rate in the transition region may show a behavior similar to the one experimentally observed. Qualitatively, this can be understood as follows: Upon termination of the $\mathrm{CO}$ beam, the surface $\mathrm{CO}$ reservoir is depleted by reaction and desorption. Consequently, the reaction rate will decrease with a given time constant. This effect competes with the increase of the oxygen coverage as a result of the decreasing $\mathrm{CO}$ induced poisoning. As both processes may proceed with different rates, the reaction rate may show a simple maximum or a dip followed by a maximum, depending on the particular reaction conditions. Note that in a simple kinetic model the dip typically turns out to be less pronounced as compared to the experiment. ${ }^{37}$ However, a coverage dependence of the $\mathrm{CO}$ adsorption energy, which can modify the transient kinetics, has so far been neglected in the model. At this point the particle defect structure can indirectly come into play again. Although the transient $\mathrm{CO}_{2}$ peak is not directly correlated to defect adsorption, it may be affected by the coverage dependence of the $\mathrm{CO}$ desorption and reaction barriers, which again depend on the surface structure. Experiments on Pd particles of different size and structure in combination with kinetic modeling taking into account such a dependence are currently in progress in our group and will help to clarify this point.

Effects induced by the heterogeneity of the system: The transient kinetics can be additionally modified by a certain degree of heterogeneity of the supported model catalyst. On the model surface, every Pd particle represents a largely isolated reaction system, as weak adsorption on the alumina support strongly suppresses interparticle diffusion. Thus, 


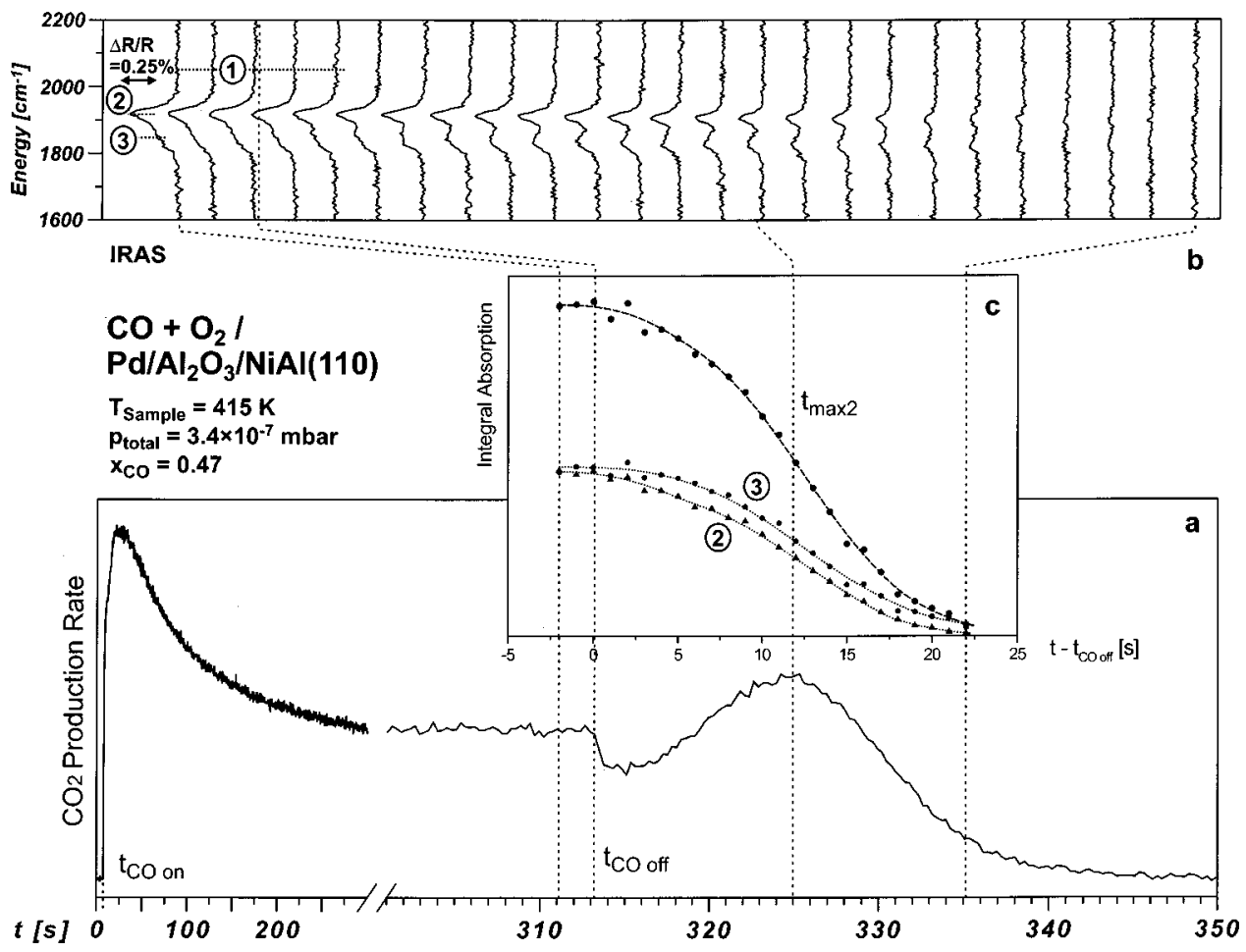

FIG. 5. Combined reactivity (a) and time-resolved IR reflection absorption experiment (b) during the transient region upon termination of the $\mathrm{CO}$ beam $\left(T_{\text {Sample }}=415 \mathrm{~K}, \quad p_{\text {total }}\right.$ $=3.4 \times 10^{-7} \mathrm{mbar}$ ). (c) Integral absorption for the IRA spectra presented in (b) and partial absorption in the features (2) and (3) indicated in the spectra on regime.

several effects can contribute to individual differences in the adsorption and the reaction rates. (1) Variations of the local effective pressure: At low reaction temperatures a large fraction of the adsorbing reactants is captured via trapping on the support and diffusion to the metal particles. This "capture zone", effect has been early discussed by Gillet et al. ${ }^{46}$ and Henry and Chapon. ${ }^{47}$ This new adsorption channel gives rise to the effect that the reactant flux per Pd surface atom depends on both the particle size and its surroundings. With increasing total pressure the transient behavior changes in a way similar to that which is found for an increasing CO flux fraction at constant total pressure. ${ }^{37}$ (2) Variations in the sticking coefficient depending on the surface and defect structure of the particle. (3) Variations in the desorption rate depending on the distribution of adsorption sites available on the individual particle. (4) Variations in the reaction rate depending on the ensemble of active sites with locally varying activation barriers present on the particle.

As a consequence, on the individual particles different steady-state coverages may coexist under given reaction conditions. This effect will be particularly important under conditions where the surface coverages sensitively depend on the reaction parameters, i.e., close to the transition region between the two reaction regimes. Finally, the total macroscopic reaction rate will be a superposition of the individual particle rates, i.e., a superposition of transients possibly ranging from type 1 (oxygen rich) to type 2 (CO rich). As a consequence, we may expect that the characteristic transient $\mathrm{CO}_{2}$ production in the transition region (i.e., the sudden decrease followed by a $\mathrm{CO}_{2}$ peak) will occur over a wider range of $\mathrm{CO}$ fluxes $x_{\mathrm{CO}}$ and may appear more pronounced. In future microkinetic simulations it will finally be necessary to include such effects in order to gain a more complete understanding of the reaction kinetics and identify and quantify specific kinetic effects. However, such simulations require a detailed knowledge of the energetic and structural properties of the model systems. Today, the availability of such data is still rather limited. Detailed structural studies in combination with molecular beam experiments on supported model catalysts with a reduced and controllable level of complexity may provide a way to address these questions.

\section{CONCLUSIONS}

In conclusion, we have applied a combined molecular beam and in situ IR reflection absorption spectroscopy approach to study the kinetics of the $\mathrm{CO}$ oxidation under steady-state and transient conditions. We have employed a supported $\mathrm{Pd}$ model catalyst, based on an ordered $\mathrm{Al}_{2} \mathrm{O}_{3}$ film on $\mathrm{NiAl}(110)$. Previously, this systems has been characterized with respect to its structural and adsorption properties. The surface of the $\mathrm{Pd}$ islands is to a large extent dominated by (111) facets. The particles are characterized by an average size of $5.5 \mathrm{~nm}$ and an island density of $10^{12} \mathrm{~cm}^{-2}$.

The steady-state reaction rate was systematically determined as a function of the $\mathrm{CO}$ flux fraction and the surface temperature. We have investigated the transient behavior of the system under conditions of continuous $\mathrm{O}_{2}$ flux and modulated $\mathrm{CO}$ flux and discuss the different types of transient behavior. In particular we have focused on the appearance of a transient $\mathrm{CO}_{2}$ peak after switching off the $\mathrm{CO}$ beam. Via systematic reactivity experiments and timeresolved IR absorption spectroscopy, we demonstrate that the observed transient behavior close to the transition 
region - at least for the model system used in this study-is not related to strong defect adsorption. Instead we suggest a combination of complementary explanations, which are related to the $\mathrm{CO}$ induced inhibition of the $\mathrm{O}_{2}$ adsorption and the intrinsic heterogeneity of the model system, resulting in a coexistence of different steady states on individual particles.

\section{ACKNOWLEDGMENTS}

This project has been funded by the Max-Planck-Society and the Deutsche Forschungsgemeinschaft. The authors are particularly grateful to Professor C. R. Henry and Dr. L. Piccolo for many helpful discussions. H.-J.F. is grateful for his support from CNRS as chercheur associé at CRMC2CNRS in Luminy.

${ }^{1}$ G. Ertl, H. Knoezinger, and J. Weitkamp, Handbook of Heterogeneous Catalysis (VCH, Weinheim, 1997).

${ }^{2}$ M. Che and C. O. Bennett, Adv. Catal. 20, 153 (1989).

${ }^{3}$ V. P. Zhdanov and B. Kasemo, Surf. Sci. Rep. 39, 25 (2000).

${ }^{4}$ V. P. Zhdanov and B. Kasemo, Surf. Sci. 405, 27 (1998).

${ }^{5}$ V. P. Zhdanov and B. Kasemo, J. Catal. 170, 377 (1997).

${ }^{6}$ D. W. Goodman, Surf. Rev. Lett. 2,9 (1995).

${ }^{7}$ H.-J. Freund, M. Bäumer, and H. Kuhlenbeck, Adv. Catal. 45, 333 (2000).

${ }^{8}$ C. R. Henry, Surf. Sci. Rep. 31, 231 (1998).

${ }^{9}$ M. Bäumer, J. Libuda, A. Sandell, H.-J. Freund, G. Graw, T. Bertrams, and H. Neddermeyer, Ber. Bunsenges. Phys. Chem. 99, 1381 (1995).

${ }^{10} \mathrm{M}$. Bäumer, J. Libuda, and H.-J. Freund, in Chemisorption and Reactivity on Supported Clusters and Thin Films, edited by M. Lambert and G. Pacchioni (Kluwer, Dordrecht 1997), p. 61.

${ }^{11}$ D. R. Rainer and D. W. Goodman, J. Mol. Catal. 131, 259 (1998).

${ }^{12}$ H.-J. Freund, Angew. Chem. Int. Ed. Engl. 36, 452 (1997).

${ }^{13}$ R. M. Jaeger, H. Kuhlenbeck, H.-J. Freund, M. Wuttig, W. Hoffmann, R. Franchy, and H. Ibach, Surf. Sci. 259, 235 (1991).

${ }^{14}$ J. Libuda, F. Winkelmann, M. Bäumer, H.-J. Freund, T. Bertrams, H. Neddermeyer, and K. Müller, Surf. Sci. 318, 61 (1994).

${ }^{15}$ R. M. Jaeger, J. Libuda, M. Bäumer, K. Homann, H. Kulenbeck, and H.-J. Freund, J. Electron Spectrosc. Relat. Phenom. 64/65, 217 (1993).

${ }^{16}$ M. Bäumer and H.-J. Freund, Prog. Surf. Sci. 61, 127 (1999).

${ }^{17}$ K. Wolter, O. Seiferth, H. Kuhlenbeck, M. Bäumer, and H.-J. Freund, Surf. Sci. 399, 190 (1998).

${ }^{18}$ K. H. Hansen, T. Worren, S. Stempel, E. Laegsgaard, M. Bäumer, H.-J.
Freund, F. Besenbacher, and I. Stensgaard, Phys. Rev. Lett. 83, 4120 (1999).

${ }^{19}$ M. Asscher and G. A. Somorjai, in Atomic and Molecular Beam Methods, edited by G. Scoles (Oxford University Press, New York, 1988), Vol. 2, p. 489.

${ }^{20}$ M. P. D’Evelyn and R. J. Madix, Surf. Sci. Rep. 3, 413 (1984).

${ }^{21}$ C. T. Rettner, D. J. Auerbach, J. C. Tully, and A. W. Kleyn, J. Phys. Chem. 100, 13021 (1996).

${ }^{22}$ J. A. Barker and D. J. Auerbach, Surf. Sci. Rep. 4, 1 (1985).

${ }^{23}$ T. Engel and G. Ertl, J. Chem. Phys. 69, 1267 (1978).

${ }^{24}$ T. Engel, J. Chem. Phys. 69, 373 (1978).

${ }^{25}$ C. T. Campbell, G. Ertl, H. Kuipers, and J. Segner, J. Chem. Phys. 73, 5863 (1980).

${ }^{26}$ L. S. Brown and S. J. Sibener, J. Chem. Phys. 90, 2807 (1989).

${ }^{27}$ L. S. Brown and S. J. Sibener, J. Chem. Phys. 89, 1163 (1988).

${ }^{28}$ I. Stará, V. Nehasil, and V. Matolín, Surf. Sci. 365, 69 (1996).

${ }^{29}$ I. Stará, V. Nehasil, and V. Matolín, Surf. Sci. 331-333, 173 (1995).

${ }^{30}$ I. Meusel, J. Hoffmann, J. Hartmann, M. Heemeier, M. Bäumer, J. Libuda, and H.-J. Freund, Catal. Lett. (in press).

${ }^{31}$ C. Becker and C. R. Henry, Catal. Lett. 43, 55 (1997).

${ }^{32}$ C. Becker and C. R. Henry, Surf. Sci. 352, 457 (1996).

${ }^{33}$ J. Libuda, I. Meusel, J. Hartmann, and H.-J. Freund, Rev. Sci. Instrum. 71, 4395 (2000).

${ }^{34}$ M. Bäumer, M. Frank, J. Libuda, S. Stempel, and H.-J. Freund, Surf. Sci. 391, 204 (1997).

${ }^{35}$ X. Guo, A. Hoffman, and J. T. Yates, Jr., J. Chem. Phys. 90, 5787 (1989).

${ }^{36}$ V. Matolín, E. Gillet, and N. Kruse, Surf. Sci. 186, L541 (1987).

${ }^{37}$ J. Libuda, I. Meusel, J. Hoffmann, J. Hartmann, L. Piccolo, C. R. Henry, and H.-J. Freund, J. Chem. Phys. (in press).

${ }^{38}$ L. Piccolo, PhD thesis, Marseille, 1999.

${ }^{39}$ L. Piccolo, C. Becker, and C. R. Henry, Appl. Surf. Sci. 164, 156 (2000).

${ }^{40} \mathrm{~T}$. Engel and G. Ertl, in The Chemical Physics of Solid Surfaces and Heterogeneous Catalysis, edited by D. A. King and D. P. Woodruff (Elsevier, New York, 1982), Vol. 4, p. 73.

${ }^{41}$ M. Ehsasi, M. Berdau, T. Rebitzki, K. P. Charle, K. Christmann, and J. H. Block, J. Chem. Phys. 98, 9177 (1993).

${ }^{42}$ C. R. Henry, C. Chapon, C. Goyhenex, and R. Monot, Surf. Sci. 272, 283 (1992).

${ }^{43}$ C. R. Henry, C. Chapon, and C. Duriez, Z. Phys. D: At., Mol. Clusters 19, 347 (1991).

${ }^{44}$ M. Frank and M. Bäumer, Phys. Chem. Chem. Phys. 2, 4265 (2000).

${ }^{45}$ F. M. Hoffmann, Surf. Sci. Rep. 3, 107 (1983).

${ }^{46}$ E. Gillet, S. Channakhone, V. Matolin, and M. Gillet, Surf. Sci. 152/153, 603 (1985).

${ }^{47}$ C. R. Henry and C. Chapon, Surf. Sci. 156, 952 (1985).

${ }^{48}$ J. Libuda, Ph.D. thesis, Bochum, 1996. 